\title{
Theoretical Study of Structure and Vibrational Spectra of Molecular and Ionic Clusters Existing in Vapour over Rubidium Chloride
}

\author{
Ismail Abubakari $^{1,2,}$, Tatiana Pogrebnaya ${ }^{1,2}$, Alexander Pogrebnoi ${ }^{1,2}$ \\ ${ }^{1}$ The Nelson Mandela African Institution of Science and Technology (NM-AIST), Arusha, Tanzania \\ ${ }^{2}$ Dept. of Materials, Energy Science and Engineering, The NM-AIST, Arusha, Tanzania
}

\section{Email address:}

ismailabubakari@yahoo.com (I. Abubakari), tatiana.pogrebnaya@nm-aist.ac.tz (T. Pogrebnaya), alexander.pogrebnoi@nm-aist.ac.tz (A. Pogrebnoi),pgamtp@mail.ru (A. Pogrebnoi)

\section{To cite this article:}

Ismail Abubakari, Tatiana Pogrebnaya, Alexander Pogrebnoi. Theoretical Study of Structure and Vibrational Spectra of Molecular and Ionic Clusters Existing in Vapour over Rubidium Chloride. American Journal of Applied Chemistry. Vol. 3, No. 6, 2015, pp. $224-231$.

doi: 10.11648/j.ajac.20150306.18

\begin{abstract}
The geometrical structure and the vibrational spectra of dimer $\mathrm{Rb}_{2} \mathrm{Cl}_{2}$, trimer $\mathrm{Rb}_{3} \mathrm{Cl}_{3}$, tetramer $\mathrm{Rb}_{4} \mathrm{Cl}_{4}$ molecules and heptaatomic $\mathrm{Rb}_{4} \mathrm{Cl}_{3}{ }^{+}, \mathrm{Rb}_{3} \mathrm{Cl}_{4}{ }^{-}$ions were studied. The cluster molecules and ions had been detected in equilibrium vapour over rubidium chloride previously. The quantum chemical calculations by DFT with hybrid functional B3P86 and MP2 methods were performed. The effective core potential with Def2-TZVP $(6 \mathrm{~s} 4 \mathrm{p} 3 \mathrm{~d})$ basis set for rubidium atom and full electron aug-cc-pVTZ $(6 \mathrm{~s} 5 \mathrm{p} 3 \mathrm{~d} 2 \mathrm{f})$ basis set for chlorine atom were used. The equilibrium configuration was confirmed to be rhomb of symmetry $D_{2 \mathrm{~h}}$ for dimer $\mathrm{Rb}_{2} \mathrm{Cl}_{2}$, distorted cube $\left(T_{\mathrm{d}}\right)$ for tetramer $\mathrm{Rb}_{4} \mathrm{Cl}_{4}$ and polyhedral $\left(C_{3 \mathrm{v}}\right)$ for heptaatomic ions $\mathrm{Rb}_{4} \mathrm{Cl}_{3}^{+}$and $\mathrm{Rb}_{3} \mathrm{Cl}_{4}^{-}$. $\mathrm{For}$ the trimer molecule $\mathrm{Rb}_{3} \mathrm{Cl}_{3}$ two isomers have been revealed: hexagonal $\left(D_{3 \mathrm{~h}}\right)$ and butterfly-shaped $\left(C_{2 \mathrm{v}}\right)$, the latter has lower energy and is proved to be predominant in equilibrium vapour in a broad temperature range.
\end{abstract}

Keywords: Ionic and Molecular Clusters, Rubidium Chloride, Geometrical Structure, Vibrational Spectra, DFT, MP2, Isomers

\section{Introduction}

Several alkali metals including rubidium may chemically combine with halogen to form different neutral and ionic clusters which exist in vapours [1-10]. These clusters are characterized by different geometrical structures, vibrational spectra, and thermodynamic properties which are mostly depend on the number of atoms composing the species [1]. The formed clusters possess specific electronic, optical, magnetic and structural properties which make them useful in different technical and scientific applications [2, 3]. These properties are also strongly depending on size and composition of the clusters. Changing the magnitude and structure of a cluster aggregate allows coming up with new materials of desired properties [11].

To investigate the structure and properties of alkali halide clusters, different experimental techniques e.g. high temperature mass spectrometry $[12,13]$, microwave absorption spectroscopy $[14,15]$ and molecular beam electric resonance [16] and theoretical methods [1, 17-21] were employed.

Different molecular and ionic associates were detected in vapour over rubidium chloride; they are dimer, trimer, and tetramer molecules and the ions $\mathrm{Rb}^{+}(\mathrm{RbCl})_{\mathrm{n}}(\mathrm{n}=1-4)$ [22].

Previously the quantum chemical methods has been used to study tri- and pentaatomic ions $\mathrm{Rb}_{2} \mathrm{Cl}^{+}, \mathrm{RbCl}_{2}^{-}, \mathrm{Rb}_{3} \mathrm{Cl}_{2}^{+}$, $\mathrm{Rb}_{2} \mathrm{Cl}_{3}^{-}$[20]. The ionic clusters were studied by density functional theory (DFT) with the Becke-Lee-Yang-Parr functional (B3LYP5), second order and fourth order MøllerPlesset perturbation theory (MP2 and MP4) using the basis sets aug-cc-pVTZ (5s4p2d1f) for Cl and cc-pVTZ (7s5p4d1f) for $\mathrm{Rb}$ [20]. This study aims the investigation of the structure and properties of neutral and heavier ionic clusters of rubidium chloride.

\section{Methodology}

The density functional theory (DFT) with hybrid functional the Becke-Perdew correlation B3P86 [23-26] and second 
order Møller-Plesset perturbation theory (MP2) implemented into PC GAMESS (General Atomic and Molecular Electronic Structure System) program [27] and Firefly version 8.1.0 [28] were used for calculation of geometrical parameters and frequencies of normal vibrations. The visualization of the geometrical structure, specification of parameters, and assignment of vibrational modes in infrared spectra was done using the Chemcraft software [29] and MacMolPlt program [30]. The effective core potentials with Def2-TZVP (6s4p3d) basis set for $\mathrm{Rb}$ atom $[31,32]$ and full electron aug-cc-pVTZ basis set for $\mathrm{Cl}(6 \mathrm{~s} 5 \mathrm{p} 3 \mathrm{~d} 2 \mathrm{f})$ atom $[32,33]$ were applied in this study. The basis sets were taken from the EMSL (The Environmental Molecular Sciences Laboratory, GAMESS US) Basis Set Exchange version 1.2.2 library [34, 35].

The Openthermo software [36] was used in calculation of the thermodynamic properties including energies $\Delta_{\mathrm{r}} E$ and enthalpies $\Delta_{\mathrm{r}} H^{\circ}(0)$ of the reactions which were calculated through the following equations:

$$
\begin{aligned}
& \Delta_{\mathrm{r}} E=\sum E_{\mathrm{i} \text { prod }}-\sum E_{\mathrm{i} \text { reactant }} \\
& \Delta_{\mathrm{r}} H^{\circ}(0)=\Delta_{r} E+\Delta_{r} \varepsilon
\end{aligned}
$$

$$
\Delta_{\mathrm{r}} \varepsilon=1 / 2 h c\left(\sum \omega_{\mathrm{i} \text { prod }}-\sum \omega_{\mathrm{i} \text { reactant }}\right)
$$

where $\sum E_{\mathrm{i} \text { prod, }}, \sum E_{\mathrm{i} \text { reactant }}$ are the sums of the total energies of the products and reactants respectively, $\Delta_{\mathrm{r}} \varepsilon$ is the zero point vibration energy correction, $\sum \omega_{i}$ prod and $\sum \omega_{i}$ reactant are the sums of the vibration frequencies of the products and reactants respectively.

\section{Results and Discussion}

\subsection{Monomer $\mathrm{RbCl}$ and dimer $\mathrm{Rb}_{2} \mathrm{Cl}_{2}$}

The properties of the diatomic $\mathrm{RbCl}$ and dimer $\mathrm{Rb}_{2} \mathrm{Cl}_{2}$ molecules was computed using three different DFT hybrid functionals, B3LYP5, B3P86 and B3PW91 and MøllerPlesset perturbation theory (MP2) for the purpose of choosing the appropriate method to be implemented in this study and estimation of uncertainties in theoretical values. The results for diatomic molecule $\mathrm{RbCl}$ together with the available

\begin{tabular}{|c|c|c|c|c|c|}
\hline Property & B3LYP5 & B3P86 & B3PW91 & MP2 & Ref data \\
\hline$R_{\mathrm{e}}(\mathrm{Rb}-\mathrm{Cl})$ & 2.878 & 2.857 & 2.860 & 2.855 & $2.787[37]$ \\
\hline$-E$ & 484.32782 & 484.42116 & 484.38973 & 483.40565 & \\
\hline$\omega_{\mathrm{e}}$ & 219 & 222 & 221 & 228 & $\begin{array}{l}228[38] \\
233[39]\end{array}$ \\
\hline$\mu_{\mathrm{e}}$ & 11.0 & 10.9 & 10.9 & 11.4 & $10.483[40]$ \\
\hline$I E_{\mathrm{vert}}$ & 8.45 & 8.66 & 8.53 & 8.52 & $\begin{array}{l}8.50 \pm 0.03[41] \\
8.3 \pm 0.1[42,43]\end{array}$ \\
\hline$E A$ & 0.58 & 0.67 & 0.60 & 0.49 & $0.543 \pm 0.01[44]$ \\
\hline
\end{tabular}
experimental data are shown in Table 1.

Table 1. Properties of the monomer molecule $\mathrm{RbCl}$.

Notes: Here and hereafter, $R_{\mathrm{e}}$ is the equilibrium internuclear distance $(\AA), E$ is the total electron energy (au), $\omega_{\mathrm{e}}$ is the fundamental frequency (cm $\left.{ }^{-1}\right), \mu_{\mathrm{e}}$ is the dipole moment (D), $I E_{\mathrm{vert}}$ and $I E_{\mathrm{ad}}$ are the ionization energies, vertical and adiabatic, respectively (eV), $E A$ is the electron affinity (eV).

As is seen the calculated internuclear distance $\left(R_{\mathrm{e}}\right)$ using three DFT hybrid functionals were overrated by $0.07-0.09 \AA$ when compared with the reference data and that of MP2 was overrated by $0.07 \AA$. Considering both DFT and MP2 methods, the results obtained show very little variation whereas DFT/B3P86 and MP2 give the best results regarding to the reference. The calculated values of frequency were underrated by $6-9 \mathrm{~cm}^{-1}(2.7-3.9 \%)$ for DFT methods while MP2 result coincides with the experimental value [38]. The results for dipole moment $\left(\mu_{\mathrm{e}}\right)$, show high deviation from reference data for the case of MP2, overrated by $0.88 \mathrm{D}$; and overrated by 0.41-0.47 D for the DFT methods.

The adiabatic ionization energy $\left(I E_{\mathrm{ad}}\right)$ was obtained as the energy difference of the $\mathrm{RbCl}^{+}$ion and neutral molecule where the internuclear separation $R_{\mathrm{e}}(\mathrm{Rb}-\mathrm{Cl})$ was optimized both for neutral and ionic species and vertical ionization energy $\left(I E_{\text {vert }}\right)$ was obtained as the energy difference of the $\mathrm{RbCl}^{+}$ion and neutral molecule where the internuclear separation $R_{\mathrm{e}}(\mathrm{Rb}-\mathrm{Cl})$ was optimized in neutral molecule only and accepted the same for the ion. Electron affinities $(E A)$ were obtained by determining the energy difference between neutral molecule and negatively charged ion. The results obtained for $I E$ and $E A$ using both DFT and MP2 methods agree well with the reference. As the optimization procedure by MP2 was not implemented for the species with multiplicity more than 1 in the software [27, 28], the $I E_{\text {ad }}$ by MP2 method was not calculated in this study.

For the dimer molecule $\mathrm{Rb}_{2} \mathrm{Cl}_{2}$, a planar cyclic structure of $D_{2 \mathrm{~h}}$ symmetry (Fig. 1a) was confirmed to be equilibrium, while linear one $\left(C_{\infty \mathrm{v}}\right)$ was found to be a saddle point on the potential energy surface. The calculated properties; internuclear distance, valence angle, vibrational spectra and enthalpy of the dissociation reaction are presented in Table 2. As seen the calculated values of internuclear distance are overrated by $0.04-0.09 \AA$ compared with literature data [45] and the values of enthalpy of dissociation reaction are in agreement with the reference data $[22,46]$.

The absence of low frequencies in the vibrational spectra of $\mathrm{Rb}_{2} \mathrm{Cl}_{2}$ indicates the rigidity of the structure; the lowest frequency being about $50 \mathrm{~cm}^{-1}$.

In the IR spectrum, three vibrational modes $\omega_{4}, \omega_{5}$, and $\omega_{6}$ have nonzero intensities but due to overlapping of $\omega_{5}$ and $\omega_{6}$ only two peaks could be seen which are asymmetrical stretching $171 \mathrm{~cm}^{-1}$ and wagging $52 \mathrm{~cm}^{-1}$ (MP2). 
Based on results for the $\mathrm{RbCl}$ and $\mathrm{Rb}_{2} \mathrm{Cl}_{2}$ molecules, it is worth to mention that the data obtained by MP2 and DFT/B3P86 hybrid functional agree better with the available literature data therefore these two methods were chosen for further computations of heavier molecular and ionic clusters.

Table 2. Properties of the dimer molecule, $\mathrm{Rb}_{2} \mathrm{Cl}_{2}$.

\begin{tabular}{|c|c|c|c|c|c|}
\hline Property & B3LYP5 & B3P86 & B3PW91 & MP2 & Ref. data \\
\hline$R_{\mathrm{e}}(\mathrm{Rb}-\mathrm{Cl})$ & 3.081 & 3.053 & 3.062 & 3.032 & $2.989[45]^{\mathrm{a}}$ \\
\hline$\alpha_{\mathrm{e}}(\mathrm{Cl}-\mathrm{Rb}-\mathrm{Cl})$ & 87.7 & 87.9 & 87.8 & 88.6 & $89.5[45]^{\mathrm{a}}$ \\
\hline$-E$ & 968.71721 & 968.90454 & 968.84018 & 966.87305 & \\
\hline$\Delta_{\mathrm{r}} E$ & 161.6 & 163.4 & 159.4 & 162.1 & \\
\hline$\Delta_{\mathrm{r}} H^{\circ}$ & 159.9 & 161.6 & 157.8 & 160.1 & $\begin{array}{l}164 \pm 11[22] \\
172.4[46]\end{array}$ \\
\hline$\omega_{1}\left(A_{\mathrm{g}}\right)$ & 158 & 163 & 161 & 172 & \\
\hline$\omega_{3}\left(B_{1 \mathrm{~g}}\right)$ & 135 & 138 & 135 & 153 & \\
\hline$\omega_{4}\left(B_{1 \mathrm{u}}\right)$ & 49 & 48 & 49 & 52 & \\
\hline$\omega_{5}\left(B_{2 u}\right)$ & 155 & 158 & 155 & 171 & \\
\hline$\omega_{6}\left(B_{3 u}\right)$ & 157 & 160 & 156 & 171 & \\
\hline$I_{4}$ & 0.94 & 0.94 & 0.94 & 0.97 & \\
\hline$I_{5}$ & 1.61 & 1.62 & 1.64 & 1.70 & \\
\hline$I_{6}$ & 1.69 & 1.69 & 1.70 & 1.65 & \\
\hline
\end{tabular}

Notes: ${ }^{a}$ The MP2 calculation. Here and hereafter, $\alpha_{\mathrm{e}}$ is the valence angle (deg). $\Delta_{\mathrm{r}} E$ and $\Delta_{\mathrm{r}} H^{\circ}(0)$ are the energy and enthalpy of the dissociation reaction $\mathrm{Rb}_{2} \mathrm{Cl}_{2} \rightleftharpoons 2 \mathrm{RbCl}\left(\mathrm{kJ} \mathrm{mol}^{-1}\right), I_{\mathrm{i}}$ are the infrared intensities $\left(\mathrm{D}^{2} \cdot \mathrm{amu}^{-1} \cdot \AA^{-2}\right)$. The reducible vibration representation reduces to $\Gamma=2 A_{\mathrm{g}}+B_{1 \mathrm{~g}}+B_{1 \mathrm{u}}+B_{2 \mathrm{u}}+B_{3 \mathrm{u}}$

\subsection{Trimers $\mathrm{Rb}_{3} \mathrm{Cl}_{3}$ and tetramer $\mathrm{Rb}_{4} \mathrm{Cl}_{4}$}

For the trimer molecule $\mathrm{Rb}_{3} \mathrm{Cl}_{3}$, three possible geometrical configurations were considered; linear of $D_{\infty \mathrm{h}}$ symmetry, hexagonal of $D_{3 \mathrm{~h}}$ symmetry and butterfly-shaped of $C_{2 \mathrm{v}}$ symmetry. The linear configuration was found to be unstable due to presence of imaginary frequencies but the rest two configurations, (Figs. $1 b$ and $1 c$ ) were confirmed to be equilibrium. The results are shown in Table 3.

Table 3. Properties of trimer $\mathrm{Rb}_{3} \mathrm{Cl}_{3}$ molecule, hexagonal $\left(D_{3 \mathrm{~h}}\right)$ and butterfly-shaped $\left(C_{2 \mathrm{v}}\right)$.

\begin{tabular}{|c|c|c|c|c|c|}
\hline $\mathrm{Rb}_{3} \mathrm{Cl}_{3}\left(D_{3 \mathrm{~h}}\right)$ & & & $\mathrm{Rb}_{3} \mathrm{Cl}_{3}\left(C_{2 \mathrm{v}}\right)$ & & \\
\hline Property & B3P86 & MP2 & Property & B3P86 & MP2 \\
\hline \multirow[t]{4}{*}{$R_{\mathrm{e}}(\mathrm{Rb}-\mathrm{Cl})$} & 3.051 & 3.032 & $R_{\mathrm{e} 1}\left(\mathrm{Rb}_{1}-\mathrm{Cl}_{4}\right)$ & 2.997 & 2.982 \\
\hline & & & $R_{\mathrm{e} 2}\left(\mathrm{Rb}_{3}-\mathrm{Cl}_{5}\right)$ & 3.132 & 3.105 \\
\hline & & & $R_{\mathrm{e} 3}\left(\mathrm{Rb}_{2}-\mathrm{Cl}_{6}\right)$ & 3.093 & 3.068 \\
\hline & & & $R_{\mathrm{e} 4}\left(\mathrm{Rb}_{3}-\mathrm{Cl}_{6}\right)$ & 3.386 & 3.295 \\
\hline$\alpha_{\mathrm{e}}(\mathrm{Rb}-\mathrm{Cl}-\mathrm{Rb})$ & 117.9 & 119.5 & $\alpha_{\mathrm{e}}\left(\mathrm{Rb}_{2}-\mathrm{Cl}_{5}-\mathrm{Rb}_{3}\right)$ & 91.8 & 91.9 \\
\hline$\beta_{\mathrm{e}}(\mathrm{Cl}-\mathrm{Rb}-\mathrm{Cl})$ & 122.1 & 120.5 & $\beta_{\mathrm{e}}\left(\mathrm{Cl}_{4}-\mathrm{Rb}_{1}-\mathrm{Cl}_{6}\right)$ & 95.4 & 93.9 \\
\hline \multirow[t]{2}{*}{$-E$} & 1453.37224 & 1451.29449 & $-E$ & 1453.37325 & 1451.29818 \\
\hline & & & $-\Delta_{\mathrm{r}} E_{\text {iso }}$ & 2.6 & 9.7 \\
\hline$\omega_{1}\left(A_{1}^{\prime}\right)$ & 176 & 191 & $\omega_{1}\left(A_{1}\right)$ & $177(1.79)$ & $185(1.82)$ \\
\hline$\omega_{2}\left(A_{1}^{\prime}\right)$ & 126 & 127 & $\omega_{2}\left(A_{1}\right)$ & $128(0.02)$ & $135(0.03)$ \\
\hline$\omega_{3}\left(A_{1}^{\prime}\right)$ & 58 & 84 & $\omega_{3}\left(A_{1}\right)$ & $90(0.25)$ & $102(0.44)$ \\
\hline$\omega_{4}\left(E^{\prime}\right)$ & 181 & 193 & $\omega_{4}\left(A_{1}\right)$ & $73(0.24)$ & $85(0.07)$ \\
\hline$\omega_{5}\left(E^{\prime}\right)$ & 134 & 142 & $\omega_{5}\left(A_{1}\right)$ & $55(1.21)$ & $57(1.23)$ \\
\hline$\omega_{6}\left(E^{\prime}\right)$ & 21 & 23 & $\omega_{6}\left(A_{1}\right)$ & $50(0.03)$ & $51(0.01)$ \\
\hline$\omega_{7}\left(A_{2}^{\prime \prime}\right)$ & 46 & 48 & $\omega_{7}\left(A_{2}\right)$ & $28(0)$ & $28(0)$ \\
\hline$\omega_{8}\left(E^{\prime \prime}\right)$ & 23 & 24 & $\omega_{8}\left(B_{1}\right)$ & $8(0.01)$ & $13(0.02)$ \\
\hline$I_{4}$ & 3.94 & 3.98 & $\omega_{9}\left(B_{2}\right)$ & $188(1.25)$ & $200(1.38)$ \\
\hline$I_{5}$ & 0.82 & 0.78 & $\omega_{10}\left(B_{2}\right)$ & $172(0.45)$ & $181(0.26)$ \\
\hline$I_{7}$ & 1.40 & 1.45 & $\omega_{11}\left(B_{2}\right)$ & $150(1.03)$ & $162(1.08)$ \\
\hline \multirow[t]{2}{*}{$I_{8}$} & 0.50 & 0.52 & $\omega_{12}\left(B_{2}\right)$ & $53(0.19)$ & $53(0.19)$ \\
\hline & & & $\mu_{\mathrm{e}}$ & 9.8 & 10.4 \\
\hline
\end{tabular}

Notes: $\Delta_{\mathrm{r}} E_{\mathrm{iso}}=E\left(C_{2 \mathrm{v}}\right)-E\left(D_{3 \mathrm{~h}}\right)$ is the relative energy of the butterfly-shaped isomer regarding the hexagonal one (kJ mol $\left.{ }^{-1}\right)$. The reducible vibration representations for $\mathrm{Rb}_{3} \mathrm{~F}_{3}$ of $D_{3 \mathrm{~h}}$ and $C_{2 \mathrm{v}}$ symmetry reduces to $\Gamma=3 A_{1}^{\prime}+3 E^{\prime}+A_{2}^{\prime \prime}+E^{\prime \prime}$ and $\Gamma=6 A_{1}+A_{2}+B_{1}+4 B_{2}$ respectively. For the $C_{2 \mathrm{v}}$ butterfly-shaped isomer, the values given in parentheses near the frequencies are infrared intensities $\left(\mathrm{D}^{2} \mathrm{amu}^{-1} \AA^{-2}\right)$.

For the hexagonal isomer $\left(D_{3 \mathrm{~h}}\right)$, one internuclear distance $R_{\mathrm{e}}(\mathrm{Rb}-\mathrm{Cl})$ and one valence angle $\alpha_{\mathrm{e}}(\mathrm{Rb}-\mathrm{Cl}-\mathrm{Rb})$ or $\beta_{\mathrm{e}}(\mathrm{Cl}-\mathrm{Rb}-$ $\mathrm{Cl})$ are needed to describe the structure; for the butterfly-shaped isomer $\left(C_{2 \mathrm{v}}\right)$, four internuclear distances $R_{\mathrm{el}}$, $R_{\mathrm{e} 2}, R_{\mathrm{e} 3}, R_{\mathrm{e} 4}$ and two valence angles $\alpha_{\mathrm{e}}\left(\mathrm{Rb}_{2}-\mathrm{Cl}_{5}-\mathrm{Rb}_{3}\right)$ and
$\beta_{\mathrm{e}}\left(\mathrm{Cl}_{4}-\mathrm{Rb}_{1}-\mathrm{Cl}_{6}\right)$ are used for the description. The butterfly-shaped configuration has lower energy, by $2.6 \mathrm{~kJ}$ $\mathrm{mol}^{-1}$ (DFT) and $10.0 \mathrm{~kJ} \mathrm{~mol}^{-1}$ (MP2), than hexagonal one.

The relative concentration of isomers $p\left(C_{2 \mathrm{v}}\right) / p\left(D_{3 \mathrm{~h}}\right)$ have been estimated using the same procedure as it was described 
previously [21]. The enthalpy of the isomerization and relative energy of isomers $\Delta_{\mathrm{r}} E_{\text {iso }}$ (MP2) for the isomerization reaction $\mathrm{Rb}_{3} \mathrm{Cl}_{3}\left(D_{3 \mathrm{~h}}\right) \rightleftharpoons \mathrm{Rb}_{3} \mathrm{Cl}_{3}\left(C_{2 \mathrm{v}}\right)$ was calculated using Eqs. (2) and (3).

The values of $p\left(C_{2 \mathrm{v}}\right) / p\left(D_{3 \mathrm{~h}}\right)$ were obtained for the

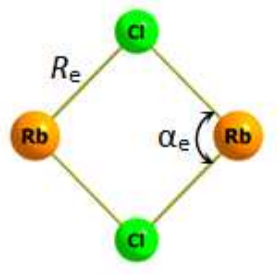

(a)

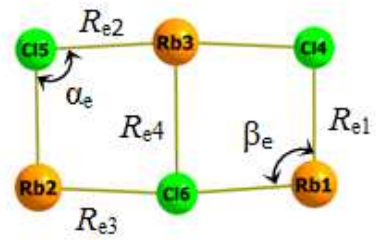

(c) temperature range between $700-2000 \mathrm{~K}$; the plot is shown in Fig. 2. As is seen the butterfly-shaped isomer is more abundant than hexagonal one and the concentration of the former decreases with temperature increase.

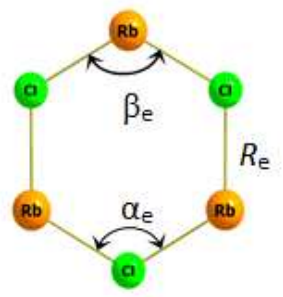

(b)

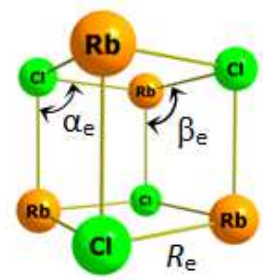

(d)

Figure 1. Equilibrium geometric structures of molecules: (a) $\mathrm{Rb}_{2} \mathrm{Cl}_{2}\left(D_{2 \mathrm{~h}}\right)$; (b) $\mathrm{Rb}_{3} \mathrm{Cl}_{3}\left(D_{3 \mathrm{~h}}\right)$; (c) $\mathrm{Rb}_{3} \mathrm{Cl}_{3}\left(C_{2 \mathrm{v}}\right)$; (d) $\mathrm{Rb}_{4} C l_{4}\left(T_{\mathrm{d}}\right)$.

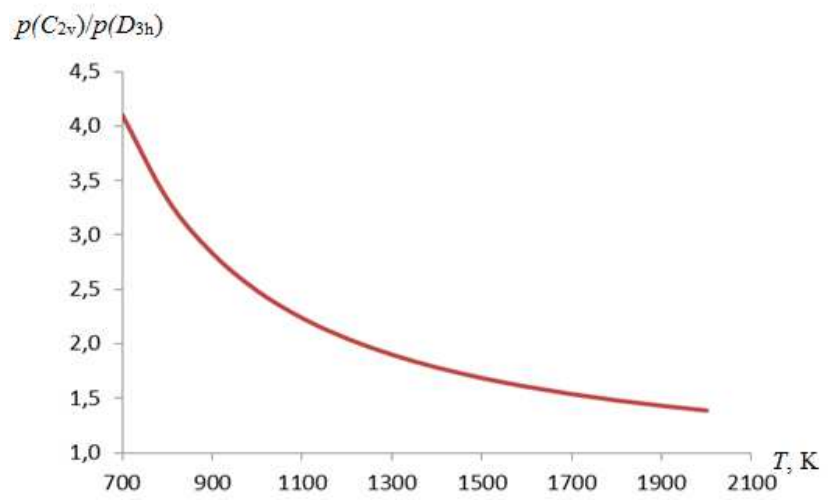

Figure 2. Temperature dependence of relative amount of the $C_{2 \mathrm{v}}$ isomer regarding to $D_{3 \mathrm{~h}}$ isomer of trimer $\mathrm{Rb}_{3} \mathrm{Cl}_{3}$ molecule.

The IR spectra of both isomers of $\mathrm{Rb}_{3} \mathrm{Cl}_{3}$ molecule are shown in Fig. 3. The most intensive bands correspond to the stretching vibration modes and bending modes have lower intensities.

When comparing the properties of $\mathrm{Rb}_{3} \mathrm{Cl}_{3}$ with $\mathrm{Rb}_{3} \mathrm{~F}_{3}$ molecule, a similarity may be noted: the same two isomers were revealed for $\mathrm{Rb}_{3} \mathrm{~F}_{3}$ [21] and the butterfly-shaped isomer was predominant in that case as well.

For the tetramer molecule $\mathrm{Rb}_{4} \mathrm{Cl}_{4}$, the geometrical configuration considered was cube with $T_{\mathrm{d}}$ symmetry (Fig. 1d) and it was confirmed to be equilibrium. The geometrical parameters and vibrational frequencies of the tetramer molecule are presented in Table 4.

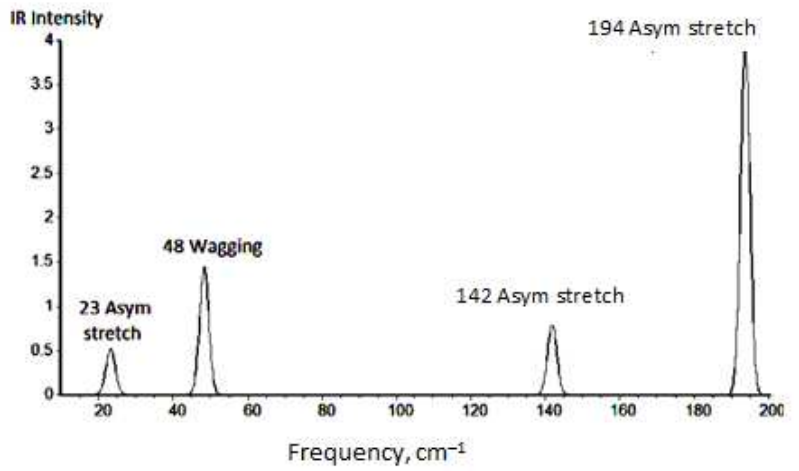

(a)

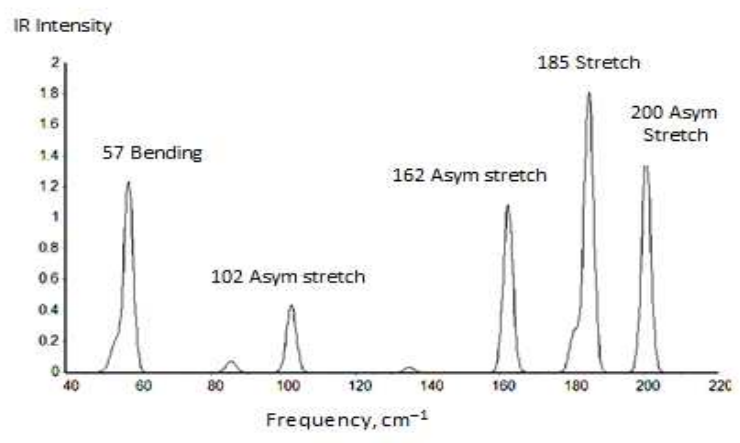

(b)

Figure 3. Theoretical IR spectra of the trimer $\mathrm{Rb}_{3} \mathrm{Cl}_{3}$ molecule calculated by MP2 method: (a) hexagonal isomer $\left(D_{3 \mathrm{~h}}\right)$; (b) butterfly-shaped isomer $\left(C_{2 \mathrm{v}}\right)$. 
Table 4. Properties of tetramer molecule $\mathrm{Rb}_{4} \mathrm{Cl}_{4}$, cube of $T_{\mathrm{d}}$ symmetry.

\begin{tabular}{lll}
\hline Property & B3P86 & MP2 \\
\hline$R_{\mathrm{e}}(\mathrm{Rb}-\mathrm{Cl})$ & 3.169 & 3.129 \\
$\alpha_{\mathrm{e}}(\mathrm{Rb}-\mathrm{Cl}-\mathrm{Rb})$ & 88.6 & 89.1 \\
$\beta_{\mathrm{e}}(\mathrm{Cl}-\mathrm{Rb}-\mathrm{Cl})$ & 91.4 & 90.9 \\
$-E$ & 1937.87064 & 1935.11485 \\
$\omega_{1}\left(A_{1}\right)$ & 138 & 145 \\
$\omega_{2}\left(A_{l}\right)$ & 80 & 80 \\
$\omega_{3}(E)$ & 119 & 128 \\
$\omega_{4}(E)$ & 51 & 61 \\
$\omega_{5}\left(T_{1}\right)$ & 116 & 127 \\
$\omega_{6}\left(T_{2}\right)$ & 141 & 151 \\
$\omega_{7}\left(T_{2}\right)$ & 137 & 146 \\
$\omega_{8}\left(T_{2}\right)$ & 49 & 41 \\
$I_{6}$ & 7.30 & 7.90 \\
$I_{7}$ & 0.38 & 0.03 \\
$I_{8}$ & 0.06 & 0.03 \\
\hline
\end{tabular}

Notes: The reducible vibration representation reduces to $\Gamma=2 A_{1}+2 E+T_{1}+$ $3 T_{2}$

One internuclear distance $R_{\mathrm{e}}(\mathrm{Rb}-\mathrm{Cl})$ and one valence angle $\alpha_{\mathrm{e}}(\mathrm{Rb}-\mathrm{Cl}-\mathrm{Rb})$ or $\beta_{\mathrm{e}}(\mathrm{Cl}-\mathrm{Rb}-\mathrm{Cl})$ are needed to describe the structure. In the IR spectrum, three vibrational modes are active but only one peak could be observed $\omega_{6}\left(T_{2}\right)$ which is assigned to asymmetrical stretching $\mathrm{Rb}-\mathrm{Cl}$ vibration; other two modes have low intensities.

\subsection{Heptaatomic Ions $\mathrm{Rb}_{4} \mathrm{Cl}_{3}^{+}$and $\mathrm{Rb}_{3} \mathrm{Cl}_{4}^{-}$}

For heptaatomic ions $\mathrm{Rb}_{4} \mathrm{Cl}_{3}{ }^{+}$and $\mathrm{Rb}_{3} \mathrm{Cl}_{4}{ }^{-}$two alternative structures were considered, polyhedral of $C_{3 \mathrm{v}}$ symmetry and two-cycled with mutually perpendicular planes of $D_{2 \mathrm{~d}}$ symmetry (Fig. 4); only polyhedral structure of symmetry $C_{3 \mathrm{v}}$ was confirmed to be equilibrium. The results for both positive and negative ions are presented in Table 5. The polyhedral structure is described by two internuclear distances $R_{\mathrm{e} 1}$ and $R_{\mathrm{e} 2}$ and three valence angles, $\alpha_{\mathrm{e}}\left(\mathrm{Rb}_{2}-\mathrm{Cl}_{5}-\mathrm{Rb}_{3}\right), \beta_{\mathrm{e}}\left(\mathrm{Rb}_{1}-\mathrm{Cl}_{4}-\mathrm{Rb}_{3}\right)$ and $\gamma_{\mathrm{e}}\left(\mathrm{Cl}_{4}-\mathrm{Rb}_{2}-\mathrm{Cl}_{7}\right)$. Compared to the $D_{2 \mathrm{~d}}$ structure, the polyhedral configurations possesses lower energy with the energy drop of $87 \mathrm{~kJ} \mathrm{~mol}^{-1}$ and $83 \mathrm{~kJ} \mathrm{~mol}^{-1}$ for $\mathrm{Rb}_{4} \mathrm{Cl}_{3}^{+}$and $\mathrm{Rb}_{3} \mathrm{Cl}_{4}^{-}$respectively, according to MP2 results.

Table 5. Properties of the heptaatomic ions $\mathrm{Rb}_{4} \mathrm{Cl}_{3}{ }^{+}$and $\mathrm{Rb}_{3} \mathrm{Cl}_{4}^{-}\left(C_{3 \mathrm{v}}\right)$.

\begin{tabular}{llllll}
\hline $\mathbf{R b}_{4} \mathbf{C l}_{3}{ }^{+}$ & & & $\mathbf{R b}_{3} \mathbf{C l}_{\mathbf{4}}{ }^{-}$ & & \\
\hline Property & $\mathbf{B 3 P 8 6}$ & MP2 & Property & B3P86 & MP2 \\
\hline$R_{\mathrm{e} 1}\left(\mathrm{Rb}_{1}-\mathrm{Cl}_{5}\right)$ & 3.191 & 3.150 & $R_{\mathrm{el}}\left(\mathrm{Rb}_{1}-\mathrm{Cl}_{4}\right)$ & 3.198 & 3.154 \\
$R_{\mathrm{e} 2}\left(\mathrm{Rb}_{3}-\mathrm{Cl}_{5}\right)$ & 3.117 & 3.089 & $R_{\mathrm{e} 2}\left(\mathrm{Rb}_{1}-\mathrm{Cl}_{6}\right)$ & 3.147 & 3.116 \\
$\alpha_{\mathrm{e}}\left(\mathrm{Cl}_{6}-\mathrm{Rb}_{2}-\mathrm{Cl}_{7}\right)$ & 87.8 & 86.6 & $\mathrm{a}_{\mathrm{e}}\left(\mathrm{Rb}_{2}-\mathrm{Cl}_{5}-\mathrm{Rb}_{3}\right)$ & 84.7 & 85.1 \\
$\beta_{\mathrm{e}}\left(\mathrm{Cl}_{5}-\mathrm{Rb}_{1}-\mathrm{Cl}_{7}\right)$ & 85.3 & 84.5 & $\beta_{\mathrm{e}}\left(\mathrm{Rb}_{1}-\mathrm{Cl}_{4}-\mathrm{Rb}_{3}\right)$ & 83.0 & 83.8 \\
$\gamma_{\mathrm{e}}\left(\mathrm{Rb}_{1}-\mathrm{Cl}_{6}-\mathrm{Rb}_{4}\right)$ & 89.2 & 89.9 & $\gamma_{\mathrm{e}}\left(\mathrm{Cl}_{4}-\mathrm{Rb}_{2}-\mathrm{Cl}_{7}\right)$ & 91.2 & 90.9 \\
$-E$ & 1477.41200 & 1475.10172 & $-E$ & 1913.72426 & 1911.20087 \\
$\omega_{1}\left(A_{1}\right)$ & $138(0.61)$ & $148(0.82)$ & $\omega_{1}\left(A_{1}\right)$ & $138(0.04)$ & $146(0.31)$ \\
$\omega_{2}\left(A_{1}\right)$ & $116(0.91)$ & $120(0.71)$ & $\omega_{2}\left(A_{1}\right)$ & $134(1.44)$ & $141(1.17)$ \\
$\omega_{3}\left(A_{1}\right)$ & $75(0.06)$ & $75(0.07)$ & $\omega_{3}\left(A_{1}\right)$ & $72(0.15)$ & $74(0.13)$ \\
$\omega_{4}\left(A_{1}\right)$ & $37(0.15)$ & $38(0.19)$ & $\omega_{4}\left(A_{1}\right)$ & $50(0.46)$ & $51(0.51)$ \\
$\omega_{5}\left(A_{2}\right)$ & $149(0)$ & $164(0)$ & $\omega_{5}\left(A_{2}\right)$ & $126(0)$ & $138(0)$ \\
$\omega_{6}(E)$ & $169(3.28)$ & $182(3.30)$ & $\omega_{6}(E)$ & $147(3.74)$ & $157(3.92)$ \\
$\omega_{7}(E)$ & $125(1.56)$ & $133(1.52)$ & $\omega_{7}(E)$ & $132(1.60)$ & $140(1.44)$ \\
$\omega_{8}(E)$ & $100(0.02)$ & $108(0.06)$ & $\omega_{8}(E)$ & $108(0.06)$ & $120(0.04)$ \\
$\omega_{9}(E)$ & $51(0.08)$ & $51(0.08)$ & $\omega_{9}(E)$ & $54(0.06)$ & $54(0.04$ \\
$\omega_{10}(E)$ & $29(0.10)$ & $29(0.12)$ & $\omega_{10}(E)$ & $31(0.26)$ & $31(0.28)$ \\
\hline
\end{tabular}

Notes: $\gamma_{\mathrm{e}}$ is the valence angle (deg). The reducible vibration representations reduce to $\Gamma=4 A_{1}+A_{2}+5 E$ for both $\mathrm{Rb}_{4} \mathrm{Cl}_{3}{ }^{+} \mathrm{and}_{\mathrm{Rb}_{3} \mathrm{Cl}_{4}{ }^{-}}$

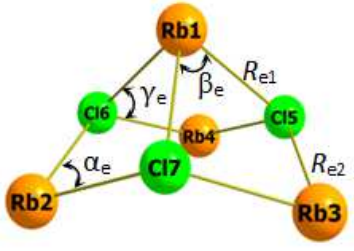

(a)

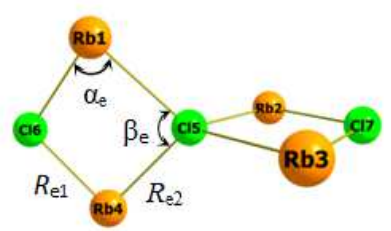

(c)

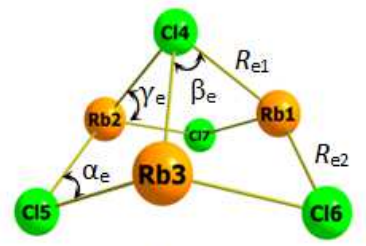

(b)

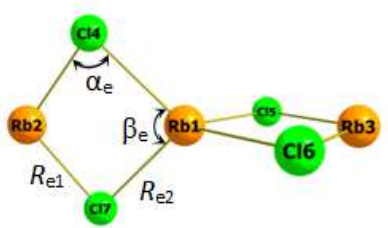

(d)

Figure 4. Geometric structures of heptaatomic ions: polyhedral of $D_{3 \mathrm{~h}}$ symmetry (a) $\mathrm{Rb}_{4} \mathrm{Cl}_{3}{ }^{+}$(b) $\mathrm{Rb}_{3} \mathrm{Cl}_{4}^{-}$: two cycled with the mutually perpendicular planes of $D_{2 \mathrm{~d}}$ symmetry (c) $\mathrm{Rb}_{4} \mathrm{Cl}_{3}^{+}$(d) $\mathrm{Rb}_{3} \mathrm{Cl}_{4}^{-}$. 
As is seen in Table 5 the respective geometrical parameters and vibrational frequencies of the positive and negative ions are close to each other. The IR spectra are shown in Fig. 5. In both spectra, the stretching vibrational modes have higher intensities than bending modes.

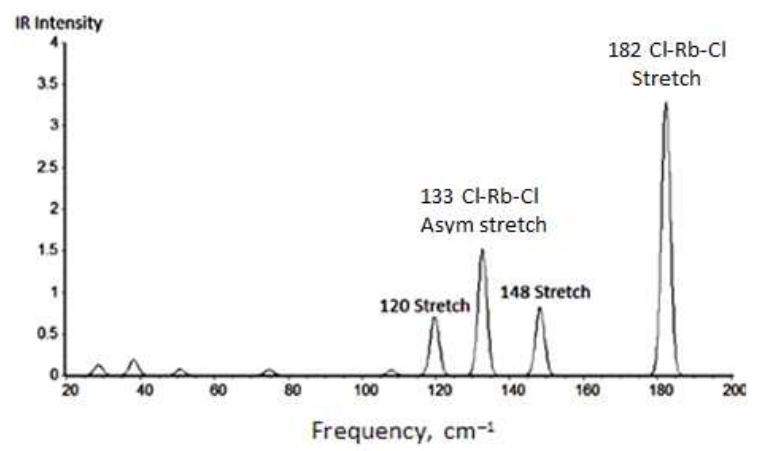

(a)

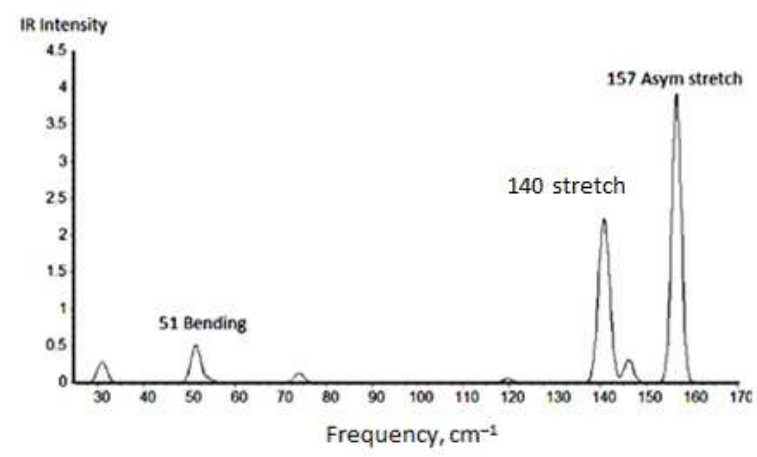

(b)

Figure 5. Theoretical IR spectra of heptaatomic ions $\left(C_{3 v}\right)$ calculated by MP2 method: (a) $\mathrm{Rb}_{4} \mathrm{Cl}_{3}^{+}$; (b) $\mathrm{Rb}_{3} \mathrm{Cl}_{4}^{-}$.

\section{Conclusion}

The properties of the trimer and tetramer molecules and heptaatomic ionic clusters have been investigated theoretically using DFT/B3P86 and MP2 methods. The corresponding parameters of the species calculated by two methods are generally in a good accordance to each other; while the internuclear distances $\mathrm{Rb}-\mathrm{Cl}$ found with DFT/B3P86 are longer by $0.02-0.04 \AA$ than those found with MP2 method. Among the species considered, for the $\mathrm{Rb}_{3} \mathrm{Cl}_{3}$ molecule two isomers, hexagonal $C_{3 \mathrm{v}}$ and butterfly-shaped $C_{2 \mathrm{v}}$, were proved to exist; the latter was evaluated to be more abundant in vapour. When compare the $\mathrm{Rb}_{3} \mathrm{Cl}_{3}$ with $\mathrm{Rb}_{3} \mathrm{~F}_{3}$ studied previously, alike features may be noted (including the existence of two isomers). The results obtained for the heptaatomic ions show similarities between the respective properties of positive and negative ions.

\section{Authors' Contributions}

All authors participate well in all steps including computation, data analysis and manuscript preparation towards production of this work.

\section{Acknowledgment}

The authors are very thankful to the Tanzania Commission for Science and Technology (COSTECH) through The Nelson Mandela African Institution of science and Technology for supporting and sponsoring this research work.

\section{Appendix}

Tables A1 to A5 contain the thermodynamic functions of the ionic and molecular clusters; trimer $\mathrm{Rb}_{3} \mathrm{~F}_{3}$, tetramer $\mathrm{Rb}_{4} \mathrm{Cl}_{4}$, and heptaatomic $\mathrm{Rb}_{4} \mathrm{Cl}_{3}^{+}$and $\mathrm{Rb}_{3} \mathrm{Cl}_{4}^{-}$. The tables include absolute temperature $T$ in $\mathrm{K}$, molar heat capacity $c_{\mathrm{p}}{ }^{\circ}$, Gibbs reduced free energy $\Phi^{\circ}$, and entropy $S^{\circ}$ which are given in $\mathrm{J} \mathrm{mol}^{-1} \mathrm{~K}^{-1}$, and enthalpy increment $H^{\circ}(T)-H^{\circ}(0)$ in $\mathrm{kJ} \mathrm{mol}^{-1}$.

Table A1. Thermodynamic functions of the $\mathrm{Rb}_{3} \mathrm{Cl}_{3}, \mathrm{C}_{2 \mathrm{v}}$. isomer.

\begin{tabular}{lllll}
\hline $\boldsymbol{T}$ & $\boldsymbol{c}_{\mathrm{p}}{ }^{\circ}$ & $\boldsymbol{S}^{\circ}$ & $\boldsymbol{H}^{\circ}(\boldsymbol{T})-\boldsymbol{H}^{\circ}(\mathbf{0})$ & $\boldsymbol{\Phi}^{\circ}$ \\
\hline 298.15 & 130.24 & 514.540 & 33.025 & 403.718 \\
700 & 132.51 & 626.923 & 85.999 & 504.067 \\
800 & 132.64 & 644.626 & 99.257 & 520.555 \\
900 & 132.71 & 660.253 & 112.524 & 535.226 \\
1000 & 132.78 & 674.239 & 125.799 & 548.440 \\
1100 & 132.82 & 686.896 & 139.079 & 560.461 \\
1200 & 132.86 & 698.455 & 152.363 & 571.486 \\
1300 & 132.89 & 709.090 & 165.649 & 581.668 \\
1400 & 132.91 & 718.938 & 178.939 & 591.124 \\
1500 & 132.93 & 728.108 & 192.230 & 599.955 \\
\hline
\end{tabular}

Table A2. Thermodynamic functions of the $\mathrm{Rb}_{3} \mathrm{Cl}_{3}, \mathrm{D}_{3 \mathrm{~h}}$ isomer.

\begin{tabular}{lllll}
\hline $\boldsymbol{T}$ & $\boldsymbol{c}_{\mathbf{p}}{ }^{\circ}$ & $\boldsymbol{S}^{\circ}$ & $\boldsymbol{H}^{\circ}(\boldsymbol{T})-\boldsymbol{H}^{\circ}(\mathbf{0})$ & $\boldsymbol{\Phi}^{\circ}$ \\
\hline 298.15 & 130.23 & 516.663 & 33.245 & 405.102 \\
700 & 132.51 & 629.039 & 86.216 & 505.873 \\
800 & 132.63 & 646.742 & 99.474 & 522.400 \\
900 & 132.70 & 662.368 & 112.741 & 537.100 \\
1000 & 132.76 & 676.355 & 126.016 & 550.339 \\
1100 & 132.84 & 689.012 & 139.296 & 562.379 \\
1200 & 132.83 & 700.570 & 152.579 & 573.421 \\
1300 & 132.81 & 711.205 & 165.866 & 583.616 \\
1400 & 132.89 & 721.053 & 179.155 & 593.085 \\
1500 & 132.92 & 730.223 & 192.446 & 601.926 \\
\hline
\end{tabular}

Table A3. Thermodynamic functions of the $\mathrm{Rb}_{4} \mathrm{Cl}_{4}, T_{\mathrm{d}}$ isomer.

\begin{tabular}{lllll}
\hline $\boldsymbol{T}$ & $\boldsymbol{c}_{\mathbf{p}}{ }^{\circ}$ & $\boldsymbol{S}^{\circ}$ & $\boldsymbol{H}^{\circ}(\boldsymbol{T})-\boldsymbol{H}^{\circ}(\mathbf{0})$ & $\boldsymbol{\Phi}^{\circ}$ \\
\hline 298.15 & 178.92 & 570.693 & 43.797 & 423.724 \\
700 & 182.18 & 725.158 & 116.611 & 558.571 \\
800 & 182.35 & 749.497 & 134.838 & 580.950 \\
900 & 182.47 & 770.982 & 153.079 & 600.894 \\
1000 & 182.56 & 790.212 & 171.331 & 618.881 \\
1100 & 182.63 & 807.615 & 189.590 & 635.260 \\
1200 & 182.67 & 823.507 & 207.854 & 650.295 \\
1300 & 182.69 & 838.129 & 226.123 & 664.188 \\
1400 & 182.74 & 851.670 & 244.394 & 677.103 \\
1500 & 182.75 & 864.278 & 262.669 & 689.165 \\
\hline
\end{tabular}


Table A4. Thermodynamic functions of the $\mathrm{Rb}_{4} \mathrm{Cl}_{3}{ }^{+}, \mathrm{C}_{3 \mathrm{v}}$ isomer.

\begin{tabular}{lllll}
\hline $\boldsymbol{T}$ & $\boldsymbol{c}_{\mathrm{p}}{ }^{\circ}$ & $\boldsymbol{S}^{\circ}$ & $\boldsymbol{H}^{\circ}(\boldsymbol{T})-\boldsymbol{H}^{\circ}(\mathbf{0})$ & $\boldsymbol{\Phi}^{\circ}$ \\
\hline 298.15 & 154.80 & 556.647 & 38.787 & 426.489 \\
700 & 157.39 & 690.161 & 101.719 & 544.848 \\
800 & 157.52 & 711.187 & 117.465 & 564.356 \\
900 & 157.64 & 729.746 & 133.222 & 581.722 \\
1000 & 157.70 & 746.357 & 148.988 & 597.369 \\
1100 & 157.73 & 761.388 & 164.759 & 611.607 \\
1200 & 157.77 & 775.115 & 180.534 & 624.670 \\
1300 & 157.82 & 787.745 & 196.313 & 636.735 \\
1400 & 157.73 & 799.440 & 212.095 & 647.944 \\
1500 & 157.77 & 810.330 & 227.878 & 658.411 \\
\hline
\end{tabular}

Table A5. Thermodynamic functions of the $\mathrm{Rb}_{3} \mathrm{Cl}_{4}^{-}, \mathrm{C}_{3 \mathrm{v}}$ isomer.

\begin{tabular}{lllll}
\hline $\boldsymbol{T}$ & $\boldsymbol{c}_{\mathbf{p}}{ }^{\circ}$ & $\boldsymbol{S}^{\circ}$ & $\boldsymbol{H}^{\circ}(\boldsymbol{T})-\boldsymbol{H}^{\circ}(\mathbf{0})$ & $\boldsymbol{\Phi}^{\circ}$ \\
\hline 298.15 & 154.92 & 546.945 & 38.729 & 416.983 \\
700 & 157.42 & 680.513 & 101.683 & 535.252 \\
800 & 157.54 & 701.542 & 117.431 & 554.753 \\
900 & 431.62 & 720.103 & 133.190 & 572.114 \\
1000 & 157.70 & 736.715 & 148.957 & 587.758 \\
1100 & 157.77 & 751.748 & 164.729 & 601.994 \\
1200 & 157.79 & 765.475 & 180.506 & 615.053 \\
1300 & 157.80 & 778.106 & 196.286 & 627.117 \\
1400 & 157.84 & 789.802 & 212.068 & 638.325 \\
1500 & 157.92 & 800.692 & 227.852 & 648.791 \\
\hline
\end{tabular}

\section{References}

[1] Cramer, C. J. (2004), Essentials of computational chemistry: theories and models. John Wiley \& Sons Ltd, $2^{\text {nd }} \mathrm{Ed}$, USA.

[2] Khanna, S. and Jena P., Assembling crystals from clusters. Phys. Rev. lett. 1993. 71(1): p. 208.

[3] Khanna, S. and Jena P., Atomic clusters: Building blocks for a class of solids. Phys. Rev. B. 1995. 51(19): p. 13705.

[4] Sarkas, H. W., Kidder, L. H., and Bowen, K. H., Photoelectron spectroscopy of color centers in negatively charged cesium iodide nanocrystals. J. Chem. Phys. 1995. 102(1): p. 57-66.

[5] Alexandrova, A. N., Boldyrev, A. I., Fu, Y. J., Yang, X., Wang, X. B., and Wang, L. S., Structure of the $\mathrm{Na}_{x} \mathrm{Cl}_{x+1}(x=1-4)$ clusters via ab initio genetic algorithm and photoelectron spectroscopy. J. Chem. Phys. 2004. 121(12): p. 5709-5719.

[6] Castleman, A. and Bowen K., Clusters: Structure, energetics, and dynamics of intermediate states of matter. J. Phys. Chem. 1996. 100(31): p. 12911-12944.

[7] Castleman Jr, A. and Khanna S., Clusters, Superatoms, and Building Blocks of New Materials. J. Phys. Chem. 2009. 113(7): p. 2664-2675.

[8] Pogrebnoi, A. M., Pogrebnaya, T. P., Kudin, L. S., and Tuyizere, S., Structure and thermodynamic properties of positive and negative cluster ions in saturated vapour over barium dichloride. Mol. Phys. 2013. 111(21): p. 3234-3245.

[9] Hishamunda, J., Girabawe, C., Pogrebnaya, T., and Pogrebnoi, A., Theoretical study of properties of $\mathrm{Cs}_{2} \mathrm{Cl}^{+}, \mathrm{CsCl}_{2}^{-}, \mathrm{Cs}_{3} \mathrm{Cl}_{2}{ }^{+}$, and $\mathrm{Cs}_{2} \mathrm{Cl}_{3}^{-}$ions: Effect of Basis set and Computation Method. Rwanda Journal. 2012. 25(1): p. 66-85.
[10] Fernandez-Lima, F. A., Nascimento, M. A. C., and da Silveira E. F., Alkali halide clusters produced by fast ion impact. Nuclear Instruments and Methods in Physics Research Section $B$ : Beam Interactions with Materials and Atoms, 2012. 273: p. 102-104.

[11] Rao, B., Khanna S., and Jena P., Designing new materials using atomic clusters. J. Clust. Sc. 1999. 10(4): p. 477-491.

[12] Chupka, W. A., Dissociation energies of some gaseous alkali halide complex ions and the hydrated ion $\left.\mathrm{K}_{(} \mathrm{H}_{2} \mathrm{O}\right)^{+}$. J. Chem. Phys. 1959. 30(2): p. 458-465.

[13] Huh, S. and Lee G., Mass spectrometric study of negative, positive, and mixed KI cluster ions by using fast Xe atom bombardment. J. Kor. Phys. Soc. 2001. 38(2): p. 107-110.

[14] Honig, A., Stitch, M., and Mandel, M., Microwave Spectra of CsF, CsCl, and CsBr. Phys. Rev. 1953. 92(4), 901.

[15] Honig, A., Mandel, M., Stitch, M., and Townes, C., Microwave spectra of the alkali halides. Phys. Rev. 1954. 96(3), 629.

[16] Fabricand, B. P., Carlson, R., Lee, C. A., and Rabi, I., Molecular Beam Investigation of Rotational Transitions. II. The Rotational Levels of $\mathrm{KBr}$ and Their Hyperfine Structure. Phys. Rev. 1953. 91(6), 1403.

[17] Aguado, A., An ab initio study of the structures and relative stabilities of doubly charged $\left[(\mathrm{NaCl})_{m}(\mathrm{Na})_{2}\right]_{2}{ }^{+}$cluster ions. J. Phys. Chem. B. 2001. 105(14): p. 2761-2765.

[18] Costa, R., Pogrebnaya T., and Pogrebnoi A., Structure and vibrational spectra of cluster ions over rubidium iodide by computational chemistry. Pan African Conference on Computing and Telecommunications in Science (PACT). IEEE. 2014. PACTAT01114: p. 52-55; doi: 10.1109/SCAT.2014.7055136.

[19] Mwanga, S. F., Pogrebnaya T. P., and Pogrebnoi A. M., Structure and properties of molecular and ionic clusters in vapour over caesium fluoride. Mol. Phys. 2015: p. 1-16.

[20] Pogrebnaya, T. P., Hishamunda, J. B., Girabawe, C., and Pogrebnoi, A. M., Theoretical study of structure, vibration spectra and thermodynamic properties of cluster ions in vapors over potassium, rubidium and cesium chlorides Chemistry for Sustainable Development. 2012, Springer. p. 353-366.

[21] Abubakari, I., Pogrebnaya, T., Pogrebnoi. A., Molecular and Ionic Clusters of Rubidium Fluoride: Theoretical Study of Structure and Vibrational Spectra. Inter. J. Comp. Theor. Chem. 2015. 3(5). p. 34-44. doi: 10.11648/j.ijctc.20150305.11

[22] Motalov, V., Pogrebnoi, A., and Kudin, L., Molecular and Ionic Associates in Vapours of Rubidium Chloride. Russ. J. Phys. Chem. (Zhurnal Fizicheskoi Khimii), 2001. 75. p. 1547-1552.

[23] Becke, A. D., Density-functional thermochemistry. III. The role of exact exchange. J. Chem. Phys. 1993. 98(7): p. 5648-5652.

[24] Perdew, J. P. and Zunger A., Self-interaction correction to density-functional approximations for many-electron systems. Phys. Rev. B. 1981. 23(10): p. 5048.

[25] Perdew, J., Phys. Rev. B. 1986, 33, 8822-8824; b) Perdew, J. P., Phys. Rev. B. 1986. 34: p. 7406-7406.

[26] Perdew, J. P., Density-functional approximation for the correlation energy of the inhomogeneous electron gas. Phys. Rev. B. 1986. 33(12): p. 8822. 
[27] Schmidt, M. W., Baldridge, K. K., Boatz, J. A., Elbert, S. T., Gordon, M. S., Jensen, J. H., Koseki, S., Matsunaga, N., Nguyen, K. A., Su, S., Windus, T. L., Dupuis, M., Montgomery, J. A., General Atomic and Molecular Electronic Structure System. J. Comput. Chem. 1993. 14: p. 1347-1363; doi:10.1002/jec.540141112.

[28] Granovsky, A. A., Firefly version 8.1.0, www http://classic.chem.msu.su/gran/firefly/index.html

[29] Zhurko G. A., Zhurko D. A., Chemcraft Version 1.7 (build 132). HTML: www.chemcraftprog.com.

[30] Bode, B. M., and Gordon, M. S., MacMolPlt version 7.4.2. J. Mol. Graphics and Modeling, 1998. 16: p. 133-138. Available: http://www.scl.ameslab.gov/MacMolPlt/.

[31] Leininger, T., Nicklass, A., Küchle, W., Stoll, H., Dolg, M., and Bergner, A., The accuracy of the pseudopotential approximation: Non-frozen-core effects for spectroscopic constants of alkali fluorides $X F(X=K, R b, C s)$. Chem. Phys. Lett. 1996. 255(4): p. 274-280.

[32] EMSL basis set exchange website: https://bse.pnl.gov/bse/portal

[33] Kendall, R. A., Dunning Jr, T. H., and Harrison, R. J., Electron affinities of the first-row atoms revisited. Systematic basis sets and wave functions. J. Chem. Phys. 1992. 96(9): p. 6796-6806.

[34] Feller, D., The role of databases in support of computational chemistry calculations. J. Comp. Chem. 1996. 17(13): p. 15711586.

[35] Schuchardt, K. L., Didier, B. T., Elsethagen, T., Sun, L., Gurumoorthi, V., Chase, J., and Windus, T. L., Basis set exchange: a community database for computational sciences. J. Chem. Info. Mod. 2007. 47(3): p. 1045-1052.

[36] Tokarev, K. L., "OpenThermo", v.1.0 Beta 1 (C) ed. http://openthermo.software.informer.com/, 2007-2009.

[37] Krasnov, K. S., Philippenko, N. V., Bobkova, V. A., Lebedeva, N. L., Morozov, E. V., Ustinova, T. I., and Romanova, G. A., Molekulyarnye postoyannye neorganicheskikh soedineniy (Handbook Molecular constants of inorganic compounds). 1979.
[38] Rice, S. A., and Klemperer, W., Spectra of the alkali halides. II. The infrared spectra of the sodium and potassium halides, $\mathrm{RbCl}$ and $\mathrm{CsCl}$. J. Chem. Phys., 1957, 27, p. 573-579.

[39] Clouser, P. L., and Gordy, W., Millimeter-wave molecular-beam spectroscopy: alkali chlorides. Phys. Rev., 1964, 134, 863

[40] Hebert, A., Lovas, F., Melendres, C., Hollowell, C., Story Jr, T., and Street Jr, K., Dipole moments of some alkali halide molecules by the molecular beam electric resonance method. $\mathrm{J}$. Chem. Phys. 1968. 48(6): p. 2824.

[41] Berkowitz, J., Photoionization mass spectrometry photoelectron spectroscopy of high temperature vapour. Adv. High Temp. Chem., 1971, 3, 123

[42] Potts, A. W.; Williams, T. A.; Price, W. C., Photoelectron spectra and electronic structure of diatomic alkali halides. Proc. Roy. Soc. London A, 1974, 341, 147

[43] Potts, A. W., and Price, W. C., Photoelectron studies of ionic materials using molecular beam techniques. Phys. Scr. 1977, 16,191

[44] Miller, T. M., Leopold, D. G., Murray, K. K., Lineberger, W. C., Electron Affinities of the Alkali Halides and the Structure of their Negative Ions. J. Chem. Phys., 1986, 85, 5, 2368; doi:10.1063/1.451091

[45] Hargittai, M., Molecular structure of metal halides. Chem. Rev. 2000. 100(6): p. 2233-2302

[46] L. V. Gurvich, V. S. Yungman, G. A. Bergman, I. V. Veitz, A. V. Gusarov, V. S. Iorish, V. Y. Leonidov, V. A. Medvedev, G. V. Belov, N. M. Aristova, L. N. Gorokhov, O. V. Dorofeeva, Y. S. Ezhov, M.E. Efimov, N. S. Krivosheya, I. I. Nazarenko, E. L. Osina, V. G. Ryabova, P. I. Tolmach, N. E. Chandamirova, E. A. Shenyavskaya, Thermodynamic Properties of individual Substances. Ivtanthermo for Windows Database on Thermodynamic Properties of Individual Substances and Thermodynamic Modeling Software. Version 3.0 (Glushko Thermocenter of RAS, Moscow, 1992-2000). 